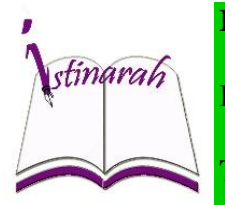

\title{
Analisis Semiotika Foto Berita di Rubrik "Pojok Gedung Sate" Bandungnewsphoto.com Edisi Jumat, 20 November 2015
}

Novrizon Marzal *)

Institut Agama Islam Negeri

Batusangkar, Sumatera Barat, Indonesia

E-mail:

novrizonmarzal@iainbatusan

gkar.ac.id

*) Corresponding Author

\begin{abstract}
Abstrak: Berkembang pesatnya media massa saat ini membuat perusahaan media merubah orientasi mereka mengikuti keiinginan masyarakat yang ingin serbainstan. Bermunculanlah media online yang berorientasi kepada foto yang dilengkapi caption, inilah yang disebut foto berita. Foto dianggap "tidak dapat berbohong", akan tetapi foto menyimpan makna dan pesan tertentu yang hendak disampaikan. Tujuan penelitian adalah untuk mengetahui makna denotatif, konotatif dan mitologi yang terkandung dalam foto berita rubrik "Pojok Gedung Sate" Bandungnewsphoto.com dengan metode penelitian kualitatif, dan analisis semiotika Roland Barthes. Hasil penelitian, rubrik "Pojok Gedung Sate" memiliki makna yang beroperasi di dalamnya. Pertama, makna denotasi terlihat dari objek yang ditampilkan dan tanda yang muncul dari foto berita. Tanda yang terdapat dalam foto berita ini termasuk makna denotasi yang merupakan gambaran nyata apa adanya tanpa spesial efek dan editing yang berlebihan sehingga terkesan alami. Kedua, makna konotasi didapat dengan menganalisis foto berita melalui enam prosedur guna mendapatkan analisis yang relevan. Hasilnya, terdapat pengolahan yang wajar pada setiap foto berita. Ketiga, mitos yang beroperasi pada tanda dalam foto berita terlihat dari objek secara langsung atau apa yang ada dalam foto dan perluasan makna yang ditunjukkan pada makna konotasi sehingga menjadi mitos.
\end{abstract}

\begin{abstract}
The mass media is growing fast and makes media companies change their orientation to follow the wishes of the people who want instant everything. emergence of online media that is oriented to photos equipped with captions, this is what is called a news photo. Photos are considered "cannot lie", but photos carry a certain meaning and message to be conveyed. The purpose of the study was to find out the denotative, connotative and mythological meanings contained in the news photo of the "Pojok Gedung Sate" Bandungnewsphoto.com rubric with qualitative research methods, and Roland Barthes semiotic analysis. The results of the study, the rubric "Pojok Gedung Sate" has a meaning that operates in it. First, the meaning of denotation can be seen from the objects displayed and the signs that appear from the news photos. The sign contained in this news photo includes the meaning of denotation which is a real picture as it is without special effects and excessive editing so that it seems natural. Second, the meaning of connotation is obtained by analyzing news photos through six procedures in order to obtain relevant analysis. As a result, there is a reasonable processing of each news photo. Third, the myth that operates on the sign in the news photo can be seen from the object directly or what is in the photo and the expansion of meaning shown in the connotative meaning so that it becomes a myth.
\end{abstract}

Kata Kunci: Media, Foto Berita, Semiotika 


\section{PENDAHULUAN}

Perkembangan tekhnologi komunikasi saat ini mengalami pergeseran, yaitu dari media massa cetak menuju media elektronik yang semakin cepat, dan masyarakat pun mulai mencoba untuk meninggalkan media massa cetak. Salah satu media massa elektronik yang sedang digemari masyarakat adalah media online. Media online ini juga produk jurnalistik online. Jurnalistik online disebut juga cyber journalisme, didefinisikan wikipedia sebagai pelaporan fakta atau peristiwa yang diproduksi dan didistribusikan melalui internet (dalam http://www.romelteamedia.com/2014/0 4/media-online-pengertian-dan.html, diakses tanggal 8 Desember 2015).

Media online ini perspepektif kajiannya terletak pada kapasitas komunikasinya. Misalnya audience yang diraih oleh media online memiliki kemampuan untuk memberi respons komentar secara langsung, yang ditulis ke dalam kolom komentar audience dalam proses komunikasi merupakan full pasticipant.

Perkembangan media online sejalur dengan makin merambahnya internet disetiap pelosok Indonesia, serta didukung juga oleh maraknya handphone yang bisa dengan mudah mengakses internet. Masih menurut Romli, media online adalah media massa "generasi ketiga" setelah media cetak (Koran, tabloid, majalah, buku) dan media elektronik (radio, televisi, film/video) (dalam http://www.romelteamedia.com/2014/0 4/media-online-pengertian-dan.html, diakses tanggal 8 Desember 2015).

Kebutuhan akan informasi pada masyarakat yang cenderung serbainstan membuat masyarakat terkadang malas untuk membaca berita dalam bentuk tulisan. Oleh karena itu, bermunculan media online yang berorientasi hanya pada berita-berita pendek atau singkat. Di samping itu juga disajikan foto sebagai pelengkapnya. Dengan melihat foto, pembaca dapat menilai apa yang terjadi atau apa makna dari sebuah foto tersebut. Penyajian foto pun dibuat semenarik mungkin dan seefektif mungkin karena foto merupakan kekuatan yang dapat memberikan gambaran secara detail dan valid sesuai fakta yang disajikan agar para pembaca lebih memahaminya.

Orientasi media online juga mengalami pergeseran yaitu dari 
berita-berita pendek yang dilengkapi dengan baik lewat media foto karena foto menuju ke foto yang dilengkapi foto dianggap "tidak dapat berbohong" dengan keterangan (caption) atau lebih memfokuskan kepada fotonya, iniah yang disebut dengan foto berita atau fotografi jurnalistik. Foto yang dihasilkan untuk pemberitaan disebut press photo atau foto berita. Foto berita berhubungan dengan keaktualan karena dapat menentukan nilai beritanya. Semakin actual suatu berita, semakin tinggi nilai beritanya. Seperti yang dikatakan oleh Effendy, "aktualitas, menurut asal katanya berarti "kini" dan "keadaan sebenarnya". Keduanya erat sangkut pautnya dengan berita yang disiarkan surat kabar" (Effendy, 1993:92) dalam (Wijaya, 2011:91)

Foto berita pemberitaan dalam bentuk gambar (pictorial journalism). Sejatinya, foto berita harus memiiki unsur $5 \mathrm{~W}+1 \mathrm{H}$ (what, who, why, when, where, dan how). Salah satu keunggulan foto, yaitu dianggap "tak bisa berbohong" dan dapat menangkap setiap detail peristiwa yang disajkan sehingga bisa menggambarkan perkembangannya dengan cepat. Hal ini sesuai dengan apa yang dikatakan Sukatendel dalam Pratikno (1987:157) bahwa kita dapat mengutarakan pesan

(Wijaya, 2011:92)

Pesan atau berita yang ingin disampaikan oleh media dapat dipahami oleh pembaca hanya dengan melihat sebuah foto. Dalam dunia jurnalistik, hal ini dikenal dengan istilah aksiomania, yaitu satu gambar seribu kata (one picture one thousand word). Hal ini menunjukan betapa dahsyatnya efek sebuah gambar dengan kata-kata (Muhtadi, 1993: 102).

Salah satu ciri yang dimiliki para juru foto jurnalistik (pewarta foto) adalah secepatnya disampaikan kehadapan pembaca. Secepatnya berarti sesuai dengan sajian kehangatan peristiwa itu sendiri, sehingga betapa baiknya sebuah foto belumlah punya arti jika hanya disimpan di laci atau album. Intinya foto yang dihasilkan harus bisa bercerita sehingga tanpa harus menjelaskannya orang sudah mengerti isi dari foto tersebut. Jadi foto yang memiliki nilai sebuah berita atau bisa untuk melengkapi sebuah cerita agar jelas faktanya. Nilai suatu foto ditentukan oleh beberapa unsur aktualitas, memiliki informasi, kejadian luar biasa, iklan, human interest dan 
universal. Lewat foto inilah kita dapat mengutarakan pesan dengan baik, kerana dianggap "foto tak bisa berbohong" (Pratikno. 1987:157)

Salah satu media yang jeli dalam melihat perkembangan media massa online dan berita foto adalah BandungNewsPhoto.com yang saat ini fokus terhadap berita foto online dengan slogan "Portal Foto Berita Bandung dan Jawa Barat". Jika kita cermati jelas bahwa bahwa portal foto berita ini sangat ingin memberikan berita seputar Bandung dan Jawa Barat.

Berkembang pesatnya media massa saat ini, perusahaan media tidak hanya berfokus terhadap penyampaian informasi saja. Perusahaan media atau Pers mulai keluar dari jalur yang seharusnya. Dalam UU No. 40 tahun 1999 diterangkan bahwa Pers adalah lembaga sosial dan wahana komunikasi massa yang melaksanakan kegiatan jurnalistik yang meliputi mencari, memperoleh, memiliki, meyimpan, mengolah, dan menyampaikan informasi baik dalam bentuk tulisan, suara, gambar, suara dan gambar, serta data dan grafik maupun dalam bentuk lainnya dengan menggunakan media cetak, media elektronik dan segala jenis saluran yang tersedia.

Media massa dituntut menjadi wadah bagi masyarakat dalam menyampaikan informasi dan memberikan informasi yang sebenarbenarnya tanpa ada kepentingan apapun didalamnya. Seperti yang dituangkan dalan Undang-Undang Dasar 1945 pasal 28 bahwa Pers adalah salah satu wujud kedaulatan rakyat dan menjadi unsur yang sangat penting untuk menciptakan kehidupan bermasyarakat, berbangsa, dan bernegara yang demokratis. Kebebasan Pers adalah kemerdekaan yang mengeluarkan pikiran dan pandapat. (Hikmat, 2011:174).

Dalam hal ini, peneliti akan meneliti tentang foto berita media online Bandungnewsphoto.com. Alasan peneliti memilih Bandungnewsphoto.com selain merupakan portal foto berita Bandung dan Jawa Barat, juga karena pada media online ini terdapat rubrik khusus yang memberitakan seputar kegiatan pemerintahan provinsi Jawa Barat atau disebut dengan nama rubrik "Pojok Gedung Sate" yang intens memberitakan kegiatan gubernur dan wakilnya. 
Foto yang disampaikan pada pada rubrik ini akan dikupas dan dipaparkan dengan detail dengan menggunakan metode Roland Barthes, sehingga pembaca dapat mengerti pesan-pesan yang disampaikan fotografer atau sebaliknya. Barthes memiliki enam prosedur untuk menganalisa sebuah foto yang peneliti gunakan sebagai objek penelitian. Prosedur ini di antaranya adalah Trick Efect, Pose, Objek, Photogenia, Astheticism, Syntax.

\section{METODE PENELITIAN}

Penelitian ini berusaha untuk mendeskripsikan makna dan pesan yang terkandung dalam sebuah foto berita. Penelitian ini menggunakan metode analisis semiotika dari Roland Barthes, peneliti menggunakan analisis semiotika karena, analisis ini lebih dapat memperdalam mengenai makna yang terkandung sebuah foto, baik itu makna denotatif, konotatif dan juga mitos.

Metode semiotika Roland Barthes terhadap berita foto melewati tiga hal, yakni:

Pertama, tahap denotasi, denotasi adalah makna paling nyata dari tanda dan merupakan hubungan antara signifier (penanda) dan signified (penanda). Denotasi merupakan reproduksi mekanis di atas film tentang objek yang ditangkap kamera. Denotasi adalah apa yang difoto, sedangkan konotasi adalah apa yang difotonya (Sobur, 2004:118).

Kedua, tahap konotasi, di mana peneliti menganalisis berita foto yang mencerminkan adanya nilai-nilai pada tanda foto tersebut. Makna konotasi menggambarkan interaksi ketika tanda bertemu dengan perasaan atau emosi pembaca serta nilai-nilai kebudayaannya. Tahap ini menggunakan enam prosedur dari Roland Barthes yakni trick effect, pose, objek, fotogenia, aestheticism, syntax. (Sunardi, 2002:183)

Ketiga, tahap mitologi, tahap mitologi ini yaitu bagaimana kebudayaan menjelaskan atau memahami beberapa aspek tentang realitas atau gejala alam. Mitos merupakan produk kelas sosial yang sudah memiliki satu dominasi. Mitos primitif misalnya, mengenai hidup dan mati, manusia dan dewa dan sebagainya. Sedangkan mitos masa kini misalnya mengenai feminitas, 
maskulinitas ilmu pengetahuan dan kesuksesan (Fiske, 1990:88).

\section{HASIL DAN PEMBAHASAN}

\section{Foto 1}

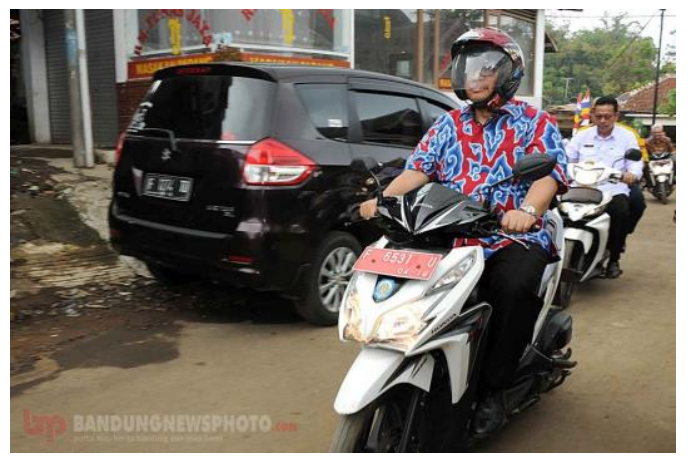

Judul : Aher Tunggangi Motor Saat Kegiatan

Gubernur

Ngamumule Lembur di

Kabupaten Sukabumi

Caption: Gubernur Jawa Barat,

Ahmad

Heryawan

mengendarai sepeda motor saat melaksankan kegiatan

Gubernur

Ngamumule

Lembur (GNL) di Desa

Nyalindung, Kecamatan

Nyalindung, Kabupaten

Sukabumi,

Kamis

(19/11/2015). Dalam GNL

kali ini diselenggarakan

berbagai macam kegiatan

usaha masyarakat seperti

kuliner, kerajinan serta

industri rumahan yang

diharapkan dapat bersaing dan berkembang tidak hanya untuk produk lokal, juga bisa dipasarkan sampai keluar daerah sehingga dapat meningkatkan tata hidup masyarakat menjadi lebih baik lagi.

\section{Denotasi}

Terlihat Gubernur Jawa Barat, Ahmad Heryawan mengendarai kendaraan dinas sepeda motor menggunakan baju batik dan memakai kelengkapan untuk berkendara berupa helm dan diikuti beberapa orang dibelakangnya.

\section{Konotasi}

Trick effect : Dilakukan pemotongan atau cropping pada foto ini.

Pose : Ahmad Heryawan terlihat fokus dan hati-hati dalam mengendarai sepeda motor.

Objek : Ahmad Heryawan sebagai Gubernur Jawa Barat, paling depan, dan di tengah.

Photogenia : Panning, bluring, dan pencahayaan yang datar.

Estetika : Foto diambil secara landsacape dengan ruang yang lebar, full shot, dan sudut pandang eye level. 
Syntax: Dalam hal ini peneliti menganalisis berdasarkan judul dan caption foto yang menceritakan Ahmad Heryawan sedang mengendarai motor saat kegiatan GNL.

\section{Foto 2}

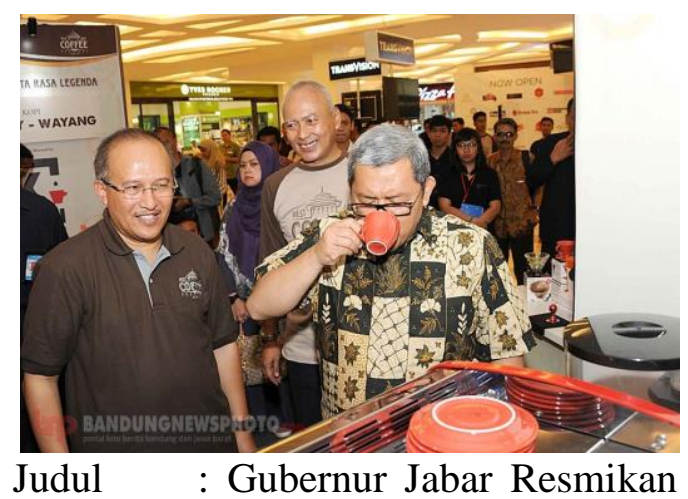

Kegiatan West Java Coffe Festival 2015 di Trans Studio Mall

Caption : Gubernur Jawa Barat, Ahmad Heryawan mencicipi kopi di salah satu stand peserta saat membuka secara resmi West Java Festival 2015 di Trans Studio Mall Bandung, Jalan Gatot Subroto, Kota Bandung, Jumat (20/11/2015). "'Saya suka mengkonsumsi kopi karena itu pencegah pikun", jelas Aher. Dalam kegiatan ini digelar berbagai macam kompetisi seperti Latte Art Throw Down, Art Bar, Barista Competition dan kompetisi seduh manual akan digelar. Selain itu ada juga workshop talkshow dan performance.

\section{Denotasi}

Terlihat Gubernur Jawa Barat, Ahmad Heryawan sedang meminum sesuatu dari cangkir berwarna merah menggunakan tangan kanan yang di dampingi oleh dua orang laki-laki dengan ekpresi tersenyum dan juga terlihat kerumuan orang di belakangnya.

\section{Konotasi}

Trick effect : Dilakukan pemotongan atau cropping pada foto ini.

Pose : Ahmad Heryawan terlihat menikmati minumannya dengan menggunakan tangan kanan, serta didampingi dua orang yang sedang tersenyum.

Objek : Ahmad Heryawan di tengah, dan dua orang yang mendampingi di samping dan belakang, serta sekelompok orang jauh di belakang. 
Photogenia : Dalam foto di atas Terlihat di dalam foto ada tiga buah terlihat bantuan dari flash, sepeda motor yang dikendarai oleh memang karena berada lima orang, Aher sendirian dan empat didalam ruangan yang lainnya berboncengan. Kemungkinan pencahyaanya kurang besar empat orang yang berada di sehingga menghasilkan cahaya belakang Aher juga dari pemerintahan. di depan lebih terang dari pada Bisa dilihat, orang yang tepat di yang di belakang, dan adanya belakang Aher memakai kemeja putih blurring. dengan penunjuk nama di dada kanan,

Estetika : Foto diambil secara normal dengan sudut pandang high dan yang paling belakang memakai angle dan pengambilan foto baju batik seperti Aher yang juga medium up.

memakai baju batik.

Peneliti berasumsi pada foto ini Syntax : Berdasarkan judul dan ada upaya membandingkan antara Aher caption diketauhi bahwa Aher dan empat orang lainnya. sedang mencicipi kopi saat Membandingkan disini maksudnya kegiatan West Java Coffe adalah membandingkan ketaatan Festival 2015 di salah satu berlalu lintas antara Aher dan empat stand peserta.

\section{PEMBAHASAN}

Denotasi

Foto 1 orang lainnya di mana yang kita ketahui Aher dalam foto ini adalah sebagai Gubernur Jawa Barat yang harus mencontohkan ketaatan dalam

Gubernur Jawa Barat, Ahmad Heryawan (Aher) mengendarai kendaraan dinas sepeda motor dengan berpakaian batik dan memakai kelengkapan untuk berkendara berupa helm serta diikuti beberapa orang dibelakangnya. Yang menjadi pertanyaan peneliti adalah kenapa hanya Aher saja yang memakai helm?

berlalu lintas kepada masyarakat Jawa Barat khusunya.

\section{Foto 2}

Gubernur Jawa Barat, Aher sedang meminum sesuatu dari cangkir berwarna merah menggunakan tangan kanan yang didampingi oleh dua orang laki-laki dengan ekspresi tersenyum dan juga terlihat kerumuan orang di 
bagian belakang. Aher sepertinya yang tidak penting dari foto sengaja sedang mengunjungi sebuah stand saat dihilangkan dan objek utama pada foto acara tertentu, dan yang sedang dicicipi ini yaitu Gebernur Jabar, Ahmad oleh Aher adalah secangkir kopi. Heryawan (Aher) diseting agar Peneliti mengetahui hal ini dari tulisan berkendara yang safety atau di dada kiri baju laki-laki yang berada menggunakan kelengkapan berkendara di sebelah kanan Aher, tulisan tersebut dan raut wajah yang mencerminkan adalah coffe.

Ekspresi wajah dua orang yang berada di kanan dan belakang Aher adalah tersenyum. Mereka sepertinya sangat senang sekali saat memdampingi Aher, mungkin stand yang dihampiri oleh Aher adalah stand mereka. Terlihat kerumunan orang berada di belakang Aher dengan antusias menyaksikan Aher yang sedang meneguk secangkir kopi. Dengan melihat foto ini pembaca di arahkan untuk terfokus kepada Aher yang terlihat menikmati kopi tersebut. Hal tersebut menggambarkan bahwa Aher adalah seorang penikmat kopi sama halnya dengan mayoritas warga Jawa Barat lainnya yang menyukai minuman kopi.

\section{Konotasi}

\section{Foto 1}

Adanya pemotongan atau cropping pada foto ini membuat bagian-bagian kefokusannya serta bisa kita perhatikan adanya teknik panning dan bluring membuat fokus gambar hanya kepada Aher.

Jika kita cermati lebih seksama lagi sebagaimana yang telah dijelaskan pada tahap denotasi, di belakang objek utama ada beberapa orang yang juga mengendarai motor tidak memakai kelengkapan berkendara tetapi "melewati" proses pemotongan. Hal tersebut sangat kontras atau berbeda dengan Aher yang menggunakan kelengkapan berkendara.

Ruang foto yang lebar membuat kesan foto lebih dramatis, serta sudut pandang yang eye level membuat makna kesejajaran, kesamaan atau sederajat dengan objek foto. Hal ini memberikan kesan bahwa Aher yang mengendarai motor "memasyarakat", ditambah dengan pencahyaan yang datar menjadikan efek yang realistis atau bersifat keseharian serta kesan 
hubungan tidak personal melalui pengambilan foto full shot.

\section{Foto 2}

Adanya pemotongan atau cropping pada foto ini membuat bagian-bagian yang tidak penting dari foto sengaja dihilangkan dan objek utama pada foto ini Gebernur Jabar, Aher diseting sedang menikmati minuman yaitu kopi menggunakan tangan kanannya. Dapat kita lihat dari ekpresi wajah Aher terlihat sangat menikmati kopi tersebut, ditambah dengan ekspresi dua orang di sisi kanan dan belakangnya yang sedang tersenyum juga mempertengas kenikmatan tersebut.

Fokus yang hanya tertuju kepada Aher, meminta perhatian hanya kepadanya, serta pengambilan foto medium up membuat foto tersebut mempunyai hubungan personal yang jelas. Pencahayaan datar memberikan kesan realistis atau keseharian yang membuat makna Aher biasa meminum kopi di kesehariannya dan dipertegas dengan caption membuat Aher adalah seorang yang menyukai kopi. Yang sedikit membingungkan peneliti adalah foto yang diambil dengan sudut pandang high angle yang mengesankan ketidakberdayaan, hal ini menurut peneliti karena kondisi di lokasi yang membuat pewarta foto terpaksa mengambil foto dengan sudut pandang tersebut.

\section{Mitos}

\section{Foto 1}

Gubernur Jawa Barat, Ahmad Heryawan (Aher) sedang mengendarai sepeda motor saat acara GNL di Desa Nyalindung agar terlihat lebih ramah dan lebih "memasyarakat". Peneliti bisa menyimpulkan hal demikian karena bisa kita baca dari caption, Aher sedang dalam suatu acara yang dilaksanakan di sebuah desa.

Mayoritas dari penduduk desa menggunakan sepeda motor, bukan mobil dan ditambah Aher sedang dalam acara GNL yang menyelenggarakan kegiatan workshop keuangan desa dan pameran produkproduk unggulan usaha masyarakat seperti kuliner, kerajinan serta industri rumahan yang tentunya peserta dari kegiatan ini adalah masyarakat desa. Untuk menuju lokasi kegiatan Aher menggunakan sepeda motor yang tentunya bukan dari ibu kota Jabar di Bandung, akan tetapi ada dua kemungkinan dalam hal ini. 
Kemungkinan pertama adalah adalah media online yang siapa saja Aher menginap di sebuah penginapan asal memiliki akses internet bisa di sekitar lokasi dan menuju ke lokasi mengakses berita ini. Walaupun menggunakan sepeda motor. sekmentasi dari Bandungnewsphoto.com Kemungkinan kedua adalah Aher adalah daerah Jawa Barat. berangkat dari Bandung menggunakan mobil dan berhenti di pusat pemerintahan desa baru kemudian mengganti kendaraannya. Akan tetapi dari dua kemungkinan tersebut tetap saja Aher di dalam foto sedang mengendarai sebuah sepeda motor dengan plat nomor berwarna merah atau kendaraan dinas.

Peneliti mencoba untuk menelaah lebih jauh ke dalam foto, bisa jadi alasan Aher menggunakan sepeda motor adalah untuk keefisienan menuju lokasi kegiatan atau bisa juga agar dianggap lebih ramah lagi kepada penduduk desa, karena selama di perjalanan Aher bisa bertegur sapa dengan masyarakat disana atau bisa peneliti katakan untuk sebuah pencitraan. Sebab, dari ketiga motor yang ada di dalam foto dan dari lima orang yang ada dalam foto hanya Aher yang menggunakan helm.

Bandungnewsphoto.com memiliki cakupan yang sangat luas dalam hal publikasi pemberitaan karena media ini

Sebagai seorang Gubernur, Aher haruslah memberikan contoh yang baik dalam hal apapun, karena Aher adalah orang nomor satu di daerah Jabar. Kesan yang timbul dari warga Jabar ketika melihat foto ini bisa jadi menganggap inilah Gubernur kita Gubernur Jabar yang taat kepada aturan, hal tersebut terjadi karena ada beberapa orang di belakang Aher yang tidak menggunakan helm. Jadi, orangorang di belakang Aher adalah sebagai pembanding.

Fakto-faktor lain yang memperkuat adanya usaha pencitraan disini adalah beberapa faktor yang berkaitan dengan hal teknis. Ada dua faktor yang memperkuat hal tersebut. Pertama adalah faktor sudut pandang yang sengaja diarahkan agar tercipta makna kesejajaran, atau kesamaan dan kedua adalah faktor pencahayaan yang mengesankan adanya efek realistis atau bersifat keseharian. Dengan dua faktor tersebut pembaca diarahkan agar bisa beranggapan inilah keseharian dari 
Aher yang ramah dan taat aturan. Maka dari hal-hal tersebut peneliti bisa berasumsi pewarta foto ataupun media berupaya dalam hal pencitraan dari Aher.

\section{Foto 2}

Gubernur Ahmad Heryawan yang sedang mencicipi kopi memberi isyarat bahwa Aher juga minum kopi. Hal ini diperkuat dengan pernyataanya di dalam caption, "Saya suka mengkonsumsi kopi karena itu pencegah pikun". Kita ketahui bahwa kopi adalah minuman semua kalangan dan mayoritas warga Jawa Barat juga menyukai kopi. Serta saat meminumnya Aher menggunakan tangan kanan yang kita ketahui makan dan minum dengan tangan kanan itu lebih baik.

Kesan yang ingin ditimbulkan oleh pewarta foto ataupun media dalam foto ini hampir sama dengan kesan pada foto pertama yakni kesan agar dianggap sama dengan warga Jabar dan memberikan contoh yang baik. Kesan sama dengan warga Jabar yang peneliti maksud adalah bahwa Aher sebagai seorang gubernur juga meminum kopi sama halnya dengan mayoritas warga Jabar, walau hal yang peneliti asumsikan ini agak sedikit kurang berhubungan, akan tetapi dengan melihat foto perhatian pembaca akan terfokus kepada Aher yang sedang meminum kopi dari cangkir berwarna merah yang membuat perhatian benarbenar fokus kepada cangkir tersebut.

Pembaca dibuat penasaran untuk pertama kalinya, apa yang sedang diminum oleh Aher. Itulah pertanyaan pertama ketika melihat foto ini. Dari beberapa tulisan disana, pembaca bisa mengetahui minuman tersebut adalah kopi dengan melihat ada dua tulisan yang bertuliskan coffe. Pertama ada di dada kiri laki-laki yang berdiri di sebelah kanan Aher. Kedua ada di pojok kiri dari foto yang sengaja tidak dipotong oleh pewarta foto. Serta acara yang bertajuk west java coffe festival tentunya hanya kopilah yang ada pada acara ini.

Mayoritas warga Jabar menyukai kopi karena iklim yang cukup dingin di daerah Jabar khusunya Ibu Kota Jabar, Bandung. Walaupun konteks dalam foto ini adalah Aher mengunjungi salah satu stand dalam acara west java coffe festival yang tentunya menyediakan kopi. Akan tetapi hal yang peneliti soroti adalah kegiatan Aher yang 
sedang menikmati kopi tersebut membuat Aher terlihat ingin sama dengan mayoritas warganya yang juga suka kopi atau bisa peneliti bahasakan seperti "inilah saya, saya juga minum kopi sama seperti yang lainnya". Ditambah lagi dengan pernyataan Aher di dalam caption yang menyatakan kesukaannya mengkonsumsi kopi.

Selanjutnya, Aher ingin mengesankan sesuatu yang dianggap benar karena merupakan anjuran dalam agama islam yakni makan dan minum dengan tangan kanan. Dalam foto Aher terlihat minum dengan tangan kanan. Walaupun hal tersebut mungkin memang kebiasaan Aher, akan tetapi hal itulah yang ditampilkannya dalam foto ini diperkuat pencahayaan yang memberikan kesan realistis menambah kesan dari hal tersebut yang mengungkapkan inilah Aher sehariharinya minum dengan tangan kanan dan suka minum kopi. Peneliti berasumsi pada foto ini pewarta foto ataupun media mencoba untuk memberikan kesan yang baik dari Aher atau bisa dikatakan salah satu pencitraan.

\section{KESIMPULAN}

Berdasarkan penelitian yang telah dilakukan dan hasil analisis yang telah dijabarkan pada pembahasan, maka peneliti menarik kesimpulan sebagai berikut:

Pertama, makna denotasi yang ada dalam foto berita yang dihasilkan pewarta foto ataupun yang diterbitkan oleh media online Bandungnewsphoto.com merupakan peristiwa sebenarnya yang direkam oleh kamera pewarta foto dan sesuai dengan fakta apa yang terjadi di lapangan. Makna denotasi yang ada di dalam foto berita rubrik "Pojok Gedung Sate" terlihat dari objek yang ditampilkan dan tanda-tanda yang muncul dari foto tersebut serta kegiatan-kegiatan yang ada dalam fotofoto penelitian menujukkan adanya makna tertentu.

Tanda-tanda yang terdapat dalam foto-foto penelitian ini semuanya termasuk makna denotasi karena merupakan gambaran yang nyata apa adanya tanpa spesial efek dan editing yang berlebihan sehingga foto-foto pada penelitian ini terkesan alami. Makna denotasi yang ada pada rubrik "Pojok Gedug Sate" ini memiliki 
studium. Studium adalah suatu kesan keseluruhan secara umum apa yang nampak pada foto-foto tersebut. Sehingga melahirkan perseptif saat pembaca melihatnya. Tahap perseptif adalah tahap transformasi gambar ke kategori verbal atau verbalisasi gambar yang bersifat imajinatif. Tahap inilah makna denotasi foto berita dapat dilihat oleh spectator (pembaca) atau yang melihat foto sesuai yang dialami sang fotografer.

Kedua, makna konotasi dari foto berita yang didapat dan diteliti tidak terlihat adanya manipulasi yang berlebihan dan mengubah makna sebenarnya dari foto berita tersebut. Manipulasi berlebihan yang dimaksud adalah manipulasi yang tidak diperbolehkan atau pengeditan foto secara berlebihan yang mengakibatkan makna yang terkandung akan hilang. Teknik dan komposisi dari foto-foto penelitian ini juga sudah sesuai dengan kaidah-kaidah dasar teknik yang ada pada ilmu fotografi. Foto berita yang dianalisis pada tahap konotasi ini memperlihatkan adanya gerakan Gubernur Jawa Barat, Ahmad Heryawan yang diarahkan atau terjadi rekayasa pose. Foto berita mengalami pemotongan atau cropping yang bertujuan untuk menggeser makna atau menghilangkan dan menambah beberapa makna tertentu sehingga mempengaruhi pembaca.

Pada dasarnya foto-foto berita ini merupakan fakta yang terjadi di lapangan dan pengolahannya adalah pengolahan yang wajar serta tidak melanggar aturan pengolahan foto.

Ketiga, mitos yang beroperasi dalam foto berita ini terlihat dari objek secara langsung atau apa yang ada di dalam foto berita yang dihasilkan pewarta foto. Foto berita rubrik "Pojok Gedung Sate" secara keseluruhan memiliki makna mitos yang terkandung di dalamnya dan terjadi kesinambungan makna pada setiap fotonya, artinya foto yang satu dengan foto yang lainnya saling berhubungan. Mitos yang terkandung pada foto berita rubrik "Pojok Gedung Sate" ini menunjukkan bagaimana hubungan antara tingkah laku atau kegiatan yang dilakukan oleh Gubernur Jawa Barat, Ahmad Heryawan.

Terdapat mitos yang hampir serupa, hal ini ditandakan dengan adanya beberapa hal yang diulangulang, yaitu ekspresi senyuman akrab 
dari Aher yang berhasil mempengaruhi

pembaca. Media online

Bandungnewsphoto.com dalam

pelaksanaanya sebagai lembaga pers

telah berhasil menjalankan salah satu

fungsinya yaitu mempengaruhi

pembaca dengan foto berita yang

diterbitkan tentang Gubernur Jabar,

Ahmad Heryawan.

\section{REFERENSI}

Effendy, Onong Uchjana. 1993. Ilmu, Teori, dan Filsafat Komunikasi. Cetakan Pertama. Bandung: Citra Aidya Bakti.

Fiske, John. 1990. Introduction of communication Studies. Second Edition. London: Routkedge.

$\begin{array}{lr}\text {.2007. Cultural and } \\ \text { Communication } & \text { Studies: } \\ \text { Sebuah Pengantar Paling }\end{array}$

Komprehensif. $\quad$ Yogyakarta:

Jalasutra

Hikmat, Mahi. 2011, Etika dan Hukum

Pers, Cetakan Pertama,

Bandung: Batic Press.

Muhtadi, Asep Saeful. 1993. Jurnalistik Pendekatan Teori

Dan Praktik, Jakarta: Logos

Wacana Ilmu.

.1999. Jurnalistik, Pendekatan

Teori dan Praktik, Jakarta:

Logos Wacana Ilmu

Pratikno, Riyono. 1987. Berbagai Aspek Ilmu Komunikasi. Bandung: CV Remaja Rosdakarya.

Sobur, Alex. 2004. Semiotika Komunikasi. Bandung: PT. Remaja Rosdakarya.
- 2009. Semiotika Komunikasi. Bandung: PT. Remaja Rosdakarya.

Sunardi, ST. 2002. Semiotika Negative. Yogyakarta : Kanal.

Wijaya, Taufan. 2011. Foto Jurnalistik: Dalam Dimensi Utuh. Klaten: CV Sahabat

Internet searching :

http://www.romelteamedia.com/2014/0 4/media-online-pengertiandan.html, diakses tanggal 8 Desember 2015 